\title{
Effect of Ag doping on the microstructure and photoluminescence of $\mathrm{ZnO}$ nanostructures
}

\author{
Volodymyr Khranovskyy, Ioannis Tsiaoussis, Martin Eriksson and Rositsa Yakimova
}

\section{Linköping University Post Print}

\section{Tweet}

N.B.: When citing this work, cite the original article.

Original Publication:

Volodymyr Khranovskyy, Ioannis Tsiaoussis, Martin Eriksson and Rositsa Yakimova, Effect of $\mathrm{Ag}$ doping on the microstructure and photoluminescence of $\mathrm{ZnO}$ nanostructures, 2014, Physica Status Solidi (a) applications and materials science, (211), 9, 2109-2114.

http://dx.doi.org/10.1002/pssa.201400008

Copyright: Wiley-VCH Verlag

http://www.wiley-vch.de/publish/en/

Postprint available at: Linköping University Electronic Press

http://urn.kb.se/resolve?urn=urn:nbn:se:liu:diva-111464 


\title{
Effect of Ag doping on the microstructure and photoluminescence of $\mathrm{ZnO}$ nanostructures
}

\author{
Volodymyr Khranovskyy $^{*},{ }^{,}$, loannis Tsiaoussis ${ }^{\star *}, 2$, Martin Eriksson $^{1}$ and Rositza Yakimova ${ }^{1}$ \\ ${ }^{1}$ Department of Physics, Chemistry and Biology, Linköping University, 58183 Linköping, Sweden \\ ${ }^{2}$ Aristotle University of Thessaloniki, 54621 Thessaloniki, Greece
}

Received ZZZ, revised ZZZ, accepted ZZZ

Published online ZZZ

Keywords: Stacking Faults, Corrugated Surface, Ag doping, p-type ZnO.

* Corresponding author: e-mail volkh@ifm.liu.se, Phone:+46-13-282663, Fax: +46-13-137568

\begin{abstract}
$\mathrm{ZnO}$ nanostructures were obtained by metal-organic chemical vapour deposition via $\mathrm{Ag}$ catalyst assisted growth in a temperature range of $200-500{ }^{\circ} \mathrm{C}$. Growth at temperatures above $500{ }^{\circ} \mathrm{C}$ resulted in vertically aligned $\mathrm{ZnO}$ nanorods. $\mathrm{Ag}$ incorporation into $\mathrm{ZnO}$ up to 0.4 at. \% promoted creation of basal plane stacking fault (BSF) defects and corrugation of the side facets of the nanorods. The presence of BSFs give rise to an additional photoluminescence peak with a wavelength of $\sim 386 \mathrm{~nm}$, which is slightly red-shifted compared to the commonly observed NBE emission at $\sim 375 \mathrm{~nm}$. The observed emission was found to be specifically observed from the side facets of the nanorods. It is suggested that this emission is due to a high concentration of BSFs in the $\mathrm{ZnO}$ as a result of an incorporation of $\mathrm{Ag}$ as acceptor dopant.
\end{abstract}

1 Introduction $\mathrm{ZnO}$ is a promising semiconductor material for optoelectronics and photonics due to possible fabrication of highly efficient light emitting diodes (LEDs) and laser diodes (LDs) [1]. It possesses the largest family of nanostructures and once the location, shape and lengthto-width ratio of the nanostructures can be controlled, it can be efficiently used in state-of-the-art bottom up semiconductor technologies. However, obtaining of $\mathrm{ZnO}$ with p-type conductivity, which is critical for most optoelectronic applications, is still posing a challenge and is practically unachievable [2]. One of the main obstacles is the self-compensation of $\mathrm{ZnO}$ as semiconductor, resulting in a high persistent electron concentration in the material $\left(\sim 10^{16} \mathrm{~cm}^{-3}\right)$, which is difficult to overcome by hole charge carriers. Earlier, group V elements have been suggested as acceptor dopants, but they create deep acceptor levels and the stability of the AX centre is a problem for As and P [3]. Group Ia elements tend to occupy the interstitial sites due to their small ionic radii, which limits their p-type doping capabilities [4]. Recent studies have been focused on group $\mathrm{Ib}$, in particular Ag, for p-type doping $[5,6]$. Ag, compared

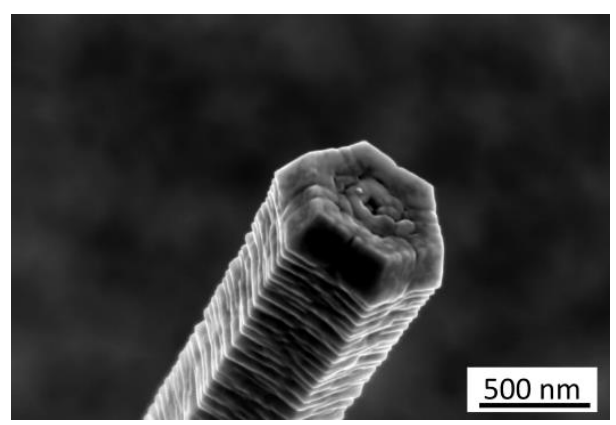

SEM image of an Ag-doped $\mathrm{ZnO}$ nanorod with corrugated side facets. The observed corrugation is accompanied by a high concentration of basal plane stacking faults.

to $\mathrm{Cu}$ and $\mathrm{Au}$, has theoretically the most shallow acceptor level at only $0.3 \mathrm{eV}$ above the valence band maximum [7]. $\mathrm{Ag}$ has the possibility to occupy two sites; $\mathrm{Zn}$ substitutional $\left(\mathrm{Ag}_{\mathrm{Zn}}\right)$ and interstitial $\left(\mathrm{Ag}_{\mathrm{i}}\right)$. The formation energy of $\mathrm{Ag}_{\mathrm{Zn}}$ is lower than $\mathrm{Ag}_{\mathrm{i}}$, so $\mathrm{Ag}$ prefers to substitute $\mathrm{Zn}$, which makes it an excellent candidate for p-type doping [8]. Finally, the radius of $\mathrm{Ag}^{2+}(0.089 \mathrm{~nm})$ is only slightly larger than that of $\mathrm{Zn}^{2+}(0.074 \mathrm{~nm})$, which may enable lower host lattice distortion in comparison to other acceptor dopants [9]. Maximum $\mathrm{Ag}$ solubility in $\mathrm{ZnO}$ is reported to be $0.76 \mathrm{~mol} . \%$ at $1200{ }^{\circ} \mathrm{C}[10]$.

As a possible acceptor dopant in $\mathrm{ZnO}, \mathrm{Ag}$ has a few additional advantages. Firstly, as a noble metal it can be used as a catalyst for growth of nanostructures via a vapour-liquid-solid process at rather low growth temperatures. Secondly, at increased Ag concentrations the dopant atoms may segregate into nanoscale $\mathrm{Ag}$ particles inside the $\mathrm{ZnO}$ matrix, which may provide exciton-plasmon coupling [11]. This can improve the internal light emission efficiency, which is beneficial for use in optoelectronics. However, as an impurity, Ag incorporation causes lattice distortion, 
strain and stress, which degrades the light emission properties of the material.

In order to address these questions, we have studied Ag catalyst assisted growth of $\mathrm{ZnO}$ nanostructures in a low temperature range $\left(200-550{ }^{\circ} \mathrm{C}\right)$ and investigated their microstructure and photoluminescence properties.

\section{Experimental details}

2.1 Sample preparation Si (100) substrates with a natural oxide were cleaned with RCI, TL1 and TL2 [12]. Then a thin layer of an organic suspension containing $\mathrm{Ag}$ particles (Ag paste) has been deposited on the substrate. The $\mathrm{ZnO}$ nanostructures were grown by atmospheric pressure metal-organic chemical vapour deposition (APMOCVD) with $\mathrm{Zn}(\mathrm{AcAc})_{2}$ from Sigma Aldrich as a precursor [13]. The precursor was loaded into an evaporator where the pressure was controlled via the evaporator temperature. The substrates were distanced from the evaporator and were located in the deposition zone. $\mathrm{ZnO}$ nanostructures were prepared at a constant precursor supersaturation with substrate temperatures in a range of 200 $-550{ }^{\circ} \mathrm{C}$. All the substrates were simultaneously places in the growth chamber, being subjected to the controlled temperature gradient in the growth zone. Ar gas was used as a carrier gas, with the flow rate 50 and $25 \mathrm{~cm}^{3} / \mathrm{min}$ respectively. The total growth time was limited to 30 minutes. More details about the APMOCVD growth of $\mathrm{ZnO}$ nanostructures can be found elsewhere [12].

2.2 Characterisation The microstructure of the nanostructures was studied by scanning electron microscopy (SEM) using a Leo 1550 Gemini SEM operated at voltages ranging from 10 to $20 \mathrm{kV}$ and using a standard aperture value of $30 \mu \mathrm{m}$. An elemental analysis of the samples was performed by ZEISS EVO 50 XVP SEM using energy dispersive X-ray spectroscopy (EDX) furnished INCA 450 (OXFORD Instruments). The operating voltage for EDX analysis was set to $20 \mathrm{kV}$. Microstructure study was carried out using conventional and high-resolution transmission electron microscopy (TEM). For cross-section transmission electron microscopy (XTEM) specimen preparation, two strips of the specimen were cut and glued face to face, and then they were mechanically thinned down to 25 $\mu \mathrm{m}$. The specimens were subsequently thinned to electron transparency by Ar ion milling with an energy of $4 \mathrm{kV}$, at a low incident angle of $4^{\circ}$ in order to avoid amorphization artifacts from the argon ions. For the conventional characterization a TEM JEM $120 \mathrm{CX}$ was used, while for the HRTEM investigation a JEM 2011 having a $0.194 \mathrm{~nm}$ point-to-point resolution was utilized. The photoluminescence (PL) from the $\mathrm{ZnO}$ nanostructures was investigated by micro-photoluminescence spectroscopy, carried out at $300 \mathrm{~K}$ with a continuous wave laser with a wavelength of $266 \mathrm{~nm}$ as an excitation source. The emitted luminescence was collected and mirrored into a single grating monochromator with a focal length of $550 \mathrm{~mm}$ and equipped with a 600 grooves $/ \mathrm{mm}$ grating and a liquid nitrogen cooled Si-CCD camera. The excited area was around 1-2 $\mu \mathrm{m}$ in diameter, providing an excitation density of 2 $\mathrm{W} / \mathrm{cm}^{2}$.

3 Results and Discussions Fig. 1a-d presents the SEM images of $\mathrm{ZnO}$ nanostructures grown at 200, 300, 400 and $500{ }^{\circ} \mathrm{C}$. Already at substrate temperature $\left(\mathrm{T}_{\mathrm{s}}\right)$ as low as $200{ }^{\circ} \mathrm{C}$, the $\mathrm{ZnO}$ deposits in an elongated shape, following the shape of the crystal grains, which is not peculiar for the growth of $\mathrm{ZnO}$ on a bare $\mathrm{Si}$ substrate at the same growth conditions [12]. This is attributed to that Ag particles available on the substrate surface provide nucleation centers for incoming $\mathrm{ZnO}$ material. The nanostructures do not possess hexagonal facets, as it is commonly observed, due to the tendency of $\mathrm{ZnO}$ to grow well faceted along the c-axis of its hexagonal structure [14]. Also, the mutual arrangement of the nanostructures is rather chaotic, reflecting absence of c-axis texture. We explain this as due to insufficient kinetic energy of $\mathrm{Zn}$ and $\mathrm{O}$ atoms for migration over the surface and occupying the most energetically favorable places. Thus, the incoming atoms are "frozen" onto the Ag provided nucleation sites. This is partially eliminated with further $\mathrm{T}_{\mathrm{s}}$ increase $\left(300{ }^{\circ} \mathrm{C}\right)$; the nanostructures start to be hexagonally faceted, and more vertically oriented due to improved c-axis texture.

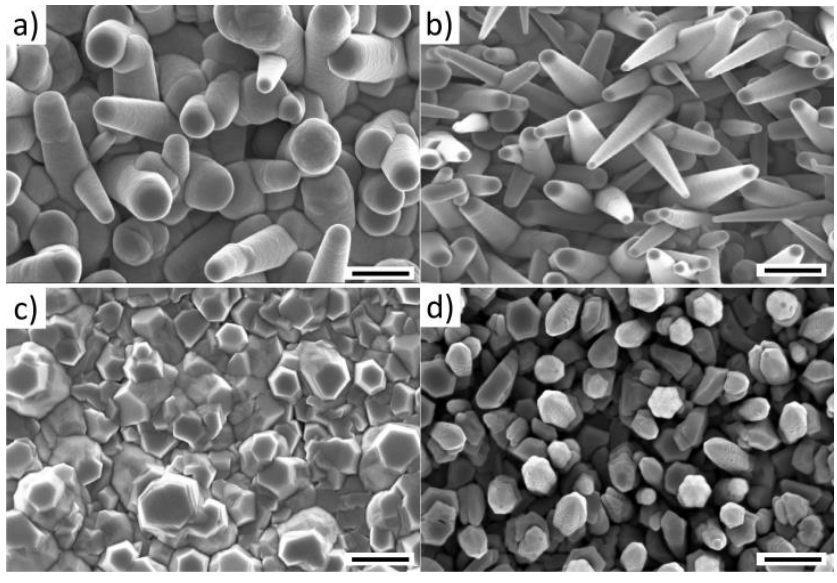

Figure $1 \mathrm{SEM}$ images of $\mathrm{ZnO}$ nanostructures of the samples grown at 200, 300, 400 and $500{ }^{\circ} \mathrm{C}$ (a, b, c, d respectively). The scale bar is $1 \mu \mathrm{m}$ for all images.

The nanostructures grown at $\mathrm{T}_{\mathrm{s}}=400{ }^{\circ} \mathrm{C}$ are already well faceted and are all oriented with their c-axis perpendicular to the substrate plane. Furthermore, the grains are located close to each other, creating a "close packed" film. Thus, the microstructure of the nanostructures grown at $400{ }^{\circ} \mathrm{C}$ looks rather similar to that grown on a bare Si substrate with a low growth rate [12]. Additionally, sharpening of the nanostructures is observed, which is due to increased kinetic energy of the adatoms provided by the higher substrate temperature, and therefore increased ability of $\mathrm{ZnO}$ atoms to attach to the crystal plane with the lowest surface energy [15]. The situation changes signifi- 
cantly for the nanostructures grown at $500{ }^{\circ} \mathrm{C}$; the grains become textured, elongated and sharp. They are not that densely packed as the previous ones; the side facets of the grains are corrugated, while their tips are hexagonally sharply tapered. Further increase of $\mathrm{T}_{\mathrm{s}}$ facilitates the observed features even more (Fig. 2a). Here the nanostructures can be divided into two types. Type 1 are the highly c-textured, grains of smaller diameter $\sim 200-500 \mathrm{~nm}$, which form the film at the bottom of the sample (Fig. 2b). Type 2 are longer and more bulky, highly faceted grains of average size $\sim 1-1.8 \mu \mathrm{m}$, called nanorods (NRs). NRs possess highly corrugated side facets, and are also sharply hexagonally tapered. The NRs have an inverse sharpening structure: their diameter tends to increase with their height (Fig. 2c). Despite the size, the nanostructures of both types are similar and possess highly corrugated side facets. Presumably, large NRs are a result of kinetically driven heterogeneous nucleation processes on the Si surface. The early nucleated cluster had a chance to grow faster and, being vertically oriented, was shadowing the other nanorods. Therefore, the diameters of the NRs are increasing with their height. The details of the morphology of the $\mathrm{ZnO}$ nanostructures are summarized in Table 1.

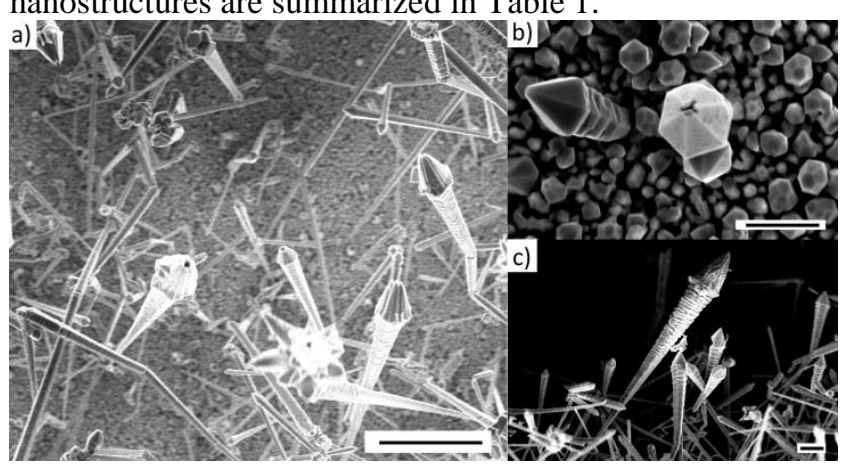

Figure 2 SEM images of $\mathrm{ZnO}$ nanostructures, grown at $550{ }^{\circ} \mathrm{C}$ : a) top view of the sample b) top view of the smaller grains of type 1 ; c) cross-section of the NRs type 2 . The scale bar is $10 \mu \mathrm{m}$ for a) and $1 \mu \mathrm{m}$ for $b$ ) and c).

The effect of side facet corrugation is an interesting phenomenon and need to be clarified. Usually, $\mathrm{ZnO}$ nanostructures grown at normal conditions by CVD or carbon thermal reduction (CTR) has flat and uniform side facets, independently of the substrates $[14,16]$. Glushenkov et al. has reported the only former case of pure $\mathrm{ZnO}$ nanostructures with unusual corrugated side facets [17].

Table 1 Details of the microstructure and the morphology of the $\mathrm{ZnO}$ nanostructures, grown at temperatures in the range 200 $500{ }^{\circ} \mathrm{C}$.

\begin{tabular}{|c|c|c|c|}
\hline $\mathbf{T}_{\mathbf{s}},{ }^{\circ} \mathbf{C}$ & Shape & Texture & Size \\
\hline 200 & Blunt tapered rods & No texture & $\begin{array}{c}\text { Rods of diame- } \\
\text { ter } 0.5 \div 1 \mu \mathrm{m}\end{array}$ \\
\hline 300 & $\begin{array}{c}\text { Blunt tapered rods, } \\
\text { slightly sharpened at } \\
\text { the end }\end{array}$ & $\begin{array}{c}\text { Some c-texture } \\
\text { appears }\end{array}$ & $\begin{array}{c}\text { Rods of diame- } \\
\text { ter } 0.5 \div 0.8 \\
\mu \mathrm{m}\end{array}$ \\
\hline 400 & Densely packed & Strong c-axis & Grains of di- \\
\hline
\end{tabular}

\begin{tabular}{|c|c|c|c|}
\hline & $\begin{array}{c}\text { grains with hexago- } \\
\text { nal faceting }\end{array}$ & texture & $\begin{array}{c}\text { ameter } 0.5 \div \\
0.8 \mu \mathrm{m}\end{array}$ \\
\hline 500 & $\begin{array}{l}\text { Densely packed hex- } \\
\text { agonally faceted } \\
\text { grains with corrugat- } \\
\text { ed surface }\end{array}$ & $\begin{array}{l}\text { Strong c-axis } \\
\text { texture }\end{array}$ & $\begin{array}{l}\text { Grains of di- } \\
\text { ameter } 0.2 \div \\
0.5 \mu \mathrm{m}\end{array}$ \\
\hline 550 & $\begin{array}{l}\text { Two types of grains: } \\
1 \text { - densely packed } \\
\text { hexagonally faceted } \\
2 \text { - bulk and long } \\
\text { NRs with inverse } \\
\text { sharpening }\end{array}$ & $\begin{array}{c}\text { Strong c-axis } \\
\text { texture for type } \\
1 .\end{array}$ & $\begin{array}{c}\text { Type } 1: 0.2 \div \\
0.5 \mu \mathrm{m} \\
\text { Type } 2: 1.0 \div \\
1.8 \mu \mathrm{m}\end{array}$ \\
\hline
\end{tabular}

It was concluded that the side surface corrugation is a result of high concentration of basal plane stacking faults (BSFs) in the material. Their appearance is attributed to the high supersaturation during the growth. Meanwhile corrugation of the side facets was numerically observed for nanostructures of $\mathrm{ZnO}$, doped with acceptor dopants. Recently Park et al. [18] reported on $\mathrm{Sb}$ doped $\mathrm{ZnO}$ nanostructures. Interestingly, the surface corrugation was only observed in the areas of the nanostructures where the $\mathrm{Sb}$ was introduced.

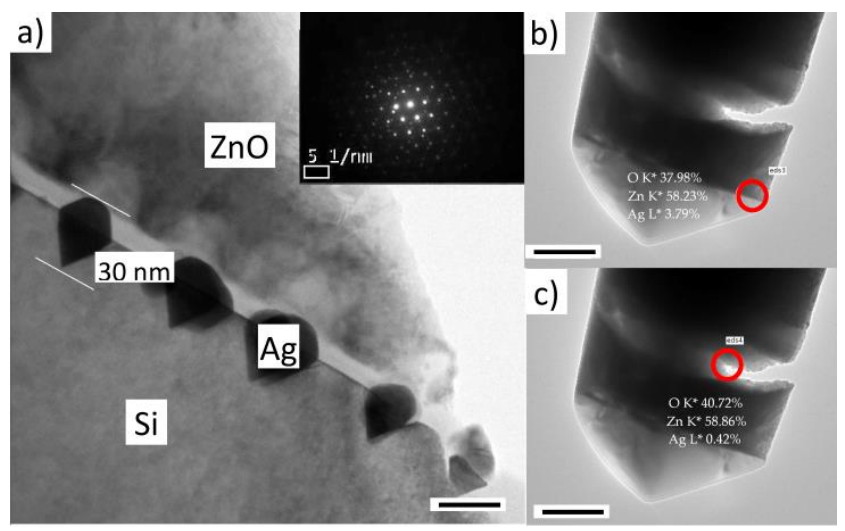

Figure 3 a) TEM image of the cross-section of the $\mathrm{Si} / \mathrm{Ag} / \mathrm{ZnO}$ interface of the NRs sample, grown at $550{ }^{\circ} \mathrm{C}$; inset is a selected area electron diffraction image of the hexagonal $\mathrm{ZnO}$ crystal structure. Ag concentration in the tip of the NRs $\sim 3.79$ at. \% (b) and inside of the NR $\sim 0.42$ at\% (c), measured by EDX analysis. The scale bar is $200 \mathrm{~nm}$ in a) and $40 \mathrm{~nm}$ in b) and c).

Taking into account the large differences in the ionic radii of $0.074 \mathrm{~nm}$ for $\mathrm{Zn}$ and $0.245 \mathrm{~nm}$ for $\mathrm{Sb}$, it is expected that incorporation of $\mathrm{Sb}$ into $\mathrm{ZnO}$ is accommodated by the creation of extended defects such as stacking faults (SFs) and dislocations.

According to Glushenkov et al. corrugation of the side surfaces of nanostructures is attributed to high SF concentration. Thus, the side facets corrugation may be attributed to acceptor, $\mathrm{Sb}$ or $\mathrm{Ag}$, incorporation. Since in our case the most corrugated side facets were observed for the NRs, we have studied them in detail. We have studied the distribution of $\mathrm{Ag}$ atoms in the NR samples. EDX analysis of the cross-section of the $\mathrm{Si} / \mathrm{Ag} / \mathrm{ZnO}$ sample performed by TEM, 
demonstrated small particles of $\mathrm{Ag}$ with a lateral size around $20 \mathrm{~nm}$ on the $\mathrm{Si} / \mathrm{ZnO}$ interface (Fig. 3).

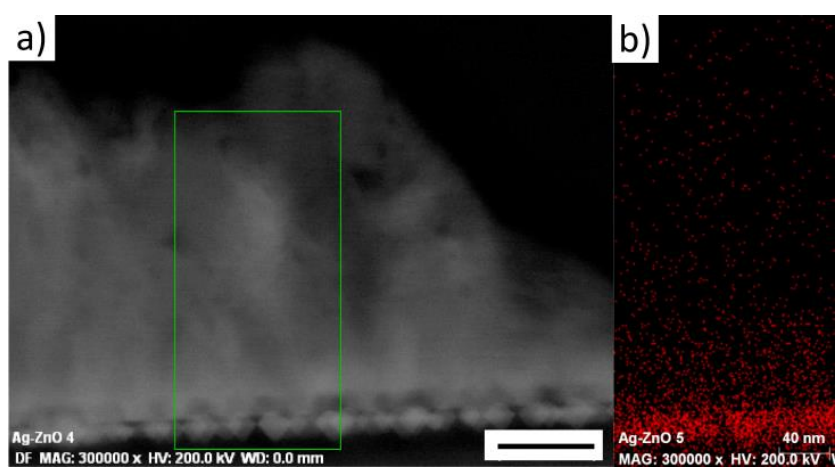

Figure 4 a) TEM image of the $\mathrm{ZnO} / \mathrm{Ag} / \mathrm{Si}$ interface: the rhombohedral particles of $\mathrm{Ag}$ are visible; the scale bar is $100 \mathrm{~nm}$. The area marked in green is used for the EDX analysis, and the distribution of $\mathrm{Ag}$ inside the $\mathrm{ZnO}$ matrix is shown in (b).

Thus, we can conclude that Ag partially stays at the $\mathrm{Si} / \mathrm{ZnO}$ interface even for the samples grown at $550{ }^{\circ} \mathrm{C}$. Figure 3 show the Ag nanoparticles of size $\sim 30 \mathrm{~nm}$, located on the $\mathrm{Si} / \mathrm{ZnO}$ interface. This, however, does not exclude that $\mathrm{Ag}$ is partially incorporated into $\mathrm{ZnO}$. We have studied the Ag content inside the NRs by EDX spectroscopy in two specific locations: inside the NRs and on its top (Fig. 3c and d). The Ag content on the top of the NR was found to be 3.8 at. \% in comparison to 0.4 at. $\%$ inside of the NR. The atomic distribution of Ag near the interface is depicted in Fig. 4.

A TEM study of the cross-section of $\mathrm{ZnO} / \mathrm{Ag} / \mathrm{Si}$ has revealed additional unusual contrast in bright field mode. The featured lines were located parallel to the substrate plane, e.g. perpendicular to the c-axis of the NR. Presuming that the reason for this is the extended defects, we have studied individual NRs by high resolution TEM. A number of basal plane [0001] stacking faults were observed, penetrating the NRs perpendicular to its c-axis (Fig. 5). BSFs were found to be quasiperiodically inserted every 5 - 10 $\mathrm{nm}$ along the NRs. It has to be mentioned that SFs are observed in both types of NRs. We attribute the appearance of BSFs as due to the Ag dopants. Earlier, it has been shown that $\mathrm{Mg}$ as an acceptor promotes the formation of SFs in GaN [19]. We believe that the same scenario can be applied in our case; Ag, having a rather different radius than $\mathrm{Zn}$, when incorporated into $\mathrm{ZnO}$ provides local strain, which favours SF formation. At present it is not clear exactly where the $\mathrm{Ag}$ atoms are located; i.e. in the proximity of SFs or not, which has to be studied in the future.

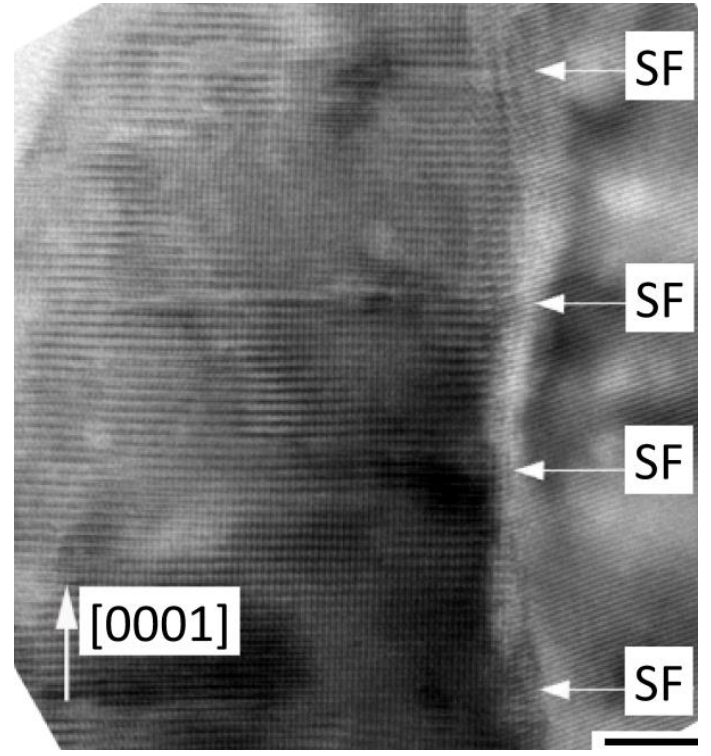

Figure 5 High resolution TEM image of ZnO NRs. The SFs are shown by arrows. The scale bar is $5 \mathrm{~nm}$.

SF may be of three types: i) basal plane SF, ii) prismatic SF, and iii) partial dislocations-terminating basalplane SF. Among them, basal plane stacking faults (BSF) are the most common type of SFs ( $90 \%)$ in wurtzite materials. Availability of SFs can modify the optical properties of the material. It was recently demonstrated, that SFs in wurtzite-structure (WZ) $\mathrm{ZnO}$, can be considered as a minimal segment of zinc blende structure (ZB) embedded in the parent crystal [20]. Due to the smaller band gap of the ZB modification, these SFs can form perfect ZB-like quantum wells (QWs) in a WZ matrix. Thus, the optical properties of $\mathrm{ZnO}$ with a lot of SFs can be significantly modified. However, ZnO SF are difficult to be identified in PL spectra, since the spectral location of the SF peak (3.314 $3.333 \mathrm{eV}$ ) overlaps with peaks from acceptor bound exciton recombination or two electron satellites (TES) of the dominating $\mathrm{D}^{0} \mathrm{X}$ peak.

We have studied micro-PL spectra of $\mathrm{ZnO}: \mathrm{Ag}$ NRs at RT by mapping the surface of the sample and probing both types of NRs (Fig. 6). It has to be noticed that the excitation laser beam was directed perpendicular to the substrate plane. Thus, both types of NRs were probed. Earlier, we suggested that the growth/formation mechanism of both NRs is identical and the only difference is their size. While the difference in their PL spectra is due to their different arrangement and thus, different areas irradiated. Smaller nanorods of type 1 are vertically oriented and therefore only their top parts are irradiated (position 1 on Fig. 6). Due to a rather shallow penetration depth of the ultraviolet laser, only a small part of the BSFs are excited. Therefore, the NBE emission at $\sim 375 \mathrm{~nm}$ is strongly dominating with a small tail, evidencing that emission at $\sim 386 \mathrm{~nm}$ is existing. However, the tail grows as the laser excitation area is 
moved toward the NRs of type 2 (positions 2-6). Finally, when only the NRs of type 2 are irradiated, both peaks are present on the PL spectrum (position 7).

In other words, while NRs of type 1 were excited from the top, some of the NRs of type 2 were tilted or located with their c-axis parallel to the substrate plane. Thus, their side facets were in fact excited by the laser beam. As one can see, top excitation of the NRs results in a regular $\mathrm{ZnO}$ luminescence with one peak at $\sim 375 \mathrm{~nm}(\sim 3.31 \mathrm{eV})$. This is commonly observed near band edge excitonic emission in $\mathrm{ZnO}$ [21]. However, once the facets of the NRs were probed, an additional peak appears in the PL spectrum on the low energy side of the previously mentioned peak. The new PL gains its maximum intensity when the side facets of NRs of type 2 are under maximum irradiation and peaks at $\sim 386 \mathrm{~nm}(\sim 3.21 \mathrm{eV})$, while the previously mentioned NBE peak still being visible at $375 \mathrm{~nm}$.

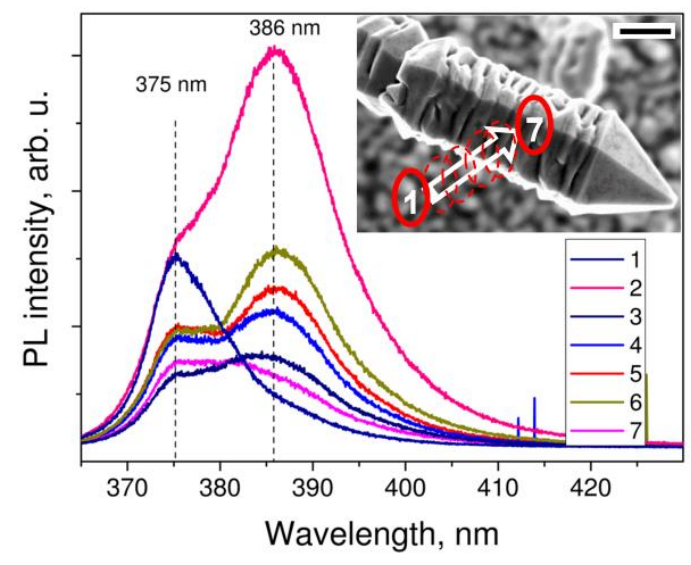

Figure 6 Micro-photoluminescence spectra of luminescence from different positions of the $\mathrm{ZnO}: \mathrm{Ag}$ NRs sample. The mapped area is shown in the inset. The mapping positions are marked in red. The scale bar in the inset is $500 \mathrm{~nm}$. Spectrum assigned as position 1 is obtained by excitation of the top planes of $\mathrm{ZnO}$ NRs. Positions 2-6 correspond to excitation of areas of both top and side planes of NRs. Position 7 corresponds to excitation of only the side facets of a NR.

The peak at $\sim 386 \mathrm{~nm}$ appears because when we excite the NRs of type 2, mostly the side facets are illuminated, thus a large number of emanating SFs are excited, which contribute to the intense PL peak $386 \mathrm{~nm}$. We have noticed that for all other samples, grown at $200-400{ }^{\circ} \mathrm{C}$, only a PL peak at $375 \mathrm{~nm}$ is observed (not shown here). This implies that the appearance of the peak at $\sim 386 \mathrm{~nm}$ is attributed to the availability of both $\mathrm{Ag}$ and SFs. The nature of the PL may be explained as an indirect exciton recombination from an electron localized in the QW in the conduction band of zinc blende $\mathrm{ZnO}$ with a hole localized near an acceptor in the proximity of a SF in wurtzite $\mathrm{ZnO}$, as it has been observed in $\mathrm{Mg}$ doped $\mathrm{GaN}$ [19]. However, a de- tailed study is necessary to clarify this recombination scheme in the $\mathrm{ZnO}$ NRs.

4 Conclusions To summarise, we have studied doping of $\mathrm{ZnO}$ by $\mathrm{Ag}$ at temperatures as low as $500{ }^{\circ} \mathrm{C}$. It has been demonstrated that $\mathrm{Ag}$ affects the growth by creating additional nucleation centres, favouring the growth of nanostructures. During growth at substrate temperatures above $500{ }^{\circ} \mathrm{C}, \mathrm{Ag}$ incorporates into the $\mathrm{ZnO}$ lattice, as well as is partially staying on the $\mathrm{Si} / \mathrm{ZnO}$ interface. NRs grown at substrate temperatures of $500{ }^{\circ} \mathrm{C}$ and above have corrugated side facets, which is attributed to the appearance of basal plane stacking faults (BSF). Their appearance is suggested to originate from $\mathrm{Ag}$ incorporation ( $\sim 0.4$ at. \%) into the ZnO NRs. Availability of BSFs affects the PL spectrum of the $\mathrm{ZnO} \mathrm{NRs}$ by providing an additional peak at $\sim 386 \mathrm{~nm}$. The peak is attributed to BSFs. The PL due to SFs is mostly observed from the side facets of the NRs. This may be useful in terms of explaining the PL properties of non-polar grown $\mathrm{ZnO}$ films, in which the possible SFs can be optically active and produce a similar PL signal.

Acknowledgements We acknowledge the Linköping Linnaeus Initiative for Novel Functional Materials (LiLi-NFM) for supporting this work. Dr. Ioannis Tsiaoussis would like to thank Dr. Valerie Potin for enabling the TEM experiments at the University of Burgundy.

\section{References}

[1] A. Djurisic, A M C Ng and X Y Chen, Prog. Quantum Electron. 34, 191 (2010).

[2] Ü. Özgür, Ya. I. Alivov, C. Liu, A. Teke, M. A. Reshchikov, S. Doğan, V. Avrutin, S.-J. Cho, and H. Morkoç, J. Appl. Phys. 98, 041301(2005).

[3] C. H. Park, S. B. Zhang, and S. H. Wei, Phys. Rev. B 66, 073202 (2002).

[4] Y.F. Yan, S. H. Wei, Phys. Stat. Sol. B 245, 641 (2008).

[5] E. Kaminska, I. Pasternak, P. Boguslawski, A. Jezierski, E. Dynowska, R. Jakiela, E. Przezdziecka, A. Piotrowska and J. Kossut, AIP Conf. Proc. 1199, 120 (2009).

[6] M. A. Myers, J. H. Lee, Z. Bi and H. Wang, J. Phys.:Condens. Matter. 24, 145802 (2012).

[7] O. Volnianska, P. Boguslawski, J. Kaczkowski, P. Jakubas, A. Jezierski and E. Kaminska, Phys. Rev. B 80, 245212 (2009).

[8] Q. Wan, Z. Xiong, J. Dai, J. Rao and F. F. Jiang, Opt. Mater. 30, 817 (2008)

[9] U. Wahl, E. Rita, J.G. Correia, T. Agne, E. Alves, J.C. Soares, Superlattices and Microstructures 39, 229 (2006).

[10] S.-T. Kuo, W.-H. Tuan, J. Shieh, S.-F. Wang, Journal of the European Ceramic Society 27, 4521 (2007).

[11] J. B. You, X. W. Zhang, Y. M. Fan, Z. G. Yin, P. F. Cai and N. F. Chen, J. Phys. D: Appl. Phys. 41, 205101 (2008).

[12] V. Khranovskyy and R. Yakimova, Physica B: Condensed Matter, 407, 1538 (2012)

[13] www.sigmaaldrich.com

[14] V. Khranovskyy, V. Lazorenko, G. Lashkarev and R. Yakimova, Journal of Luminescence 132, 2643 (2012). 
[15] V. Khranovskyy, I. Tsiaoussis, L. Hultman and R. Yakimova, Nanotechnology 22, 185603 (2011); V. Khranovskyy, A. Ulyashin, G. Lashkarev, B.G. Svensson, R. Yakimova, Thin Solid Films 516, 1396 (2008).

[16] V. Khranovskyy, I. Tsiaoussis, G. R. Yazdi, L. Hultman and R. Yakimova, Journal of Crystal Growth 312, 327 (2010).

[17] A. M. Glushenkov, H. Zhang, J. Zou, G. Qing Lu, Y. Chen, Journal of Crystal Growth 310, 3139 (2008)

[18] J.-W. Kang, Y.-S. Choi, M. Choe, N.-Y. Kim, T. Lee, B.-J. Kim, C. W. Tu and S.-J. Park, Nanotechnology 23, 495712 (2012).

[19] P. Paskov, R. Schifano, B. Monemar, T. Paskova, S. Figge and D. Hommel, J. Appl. Phys. 98, 093519 (2005).

[20] V. Khranovskyy, A. M. Glushenkov, Y. Chen, A. Khalid, H.Zhang, L. Hultman, B. Monemar and R. Yakimova, Nanotechnology 24, 215202 (2013).

[21] V. Khranovskyy, R. Yakimova, F. Karlsson, P.-O. Holtz, Z. N. Urgessa, O. S. Oluwafemi, J. R. Botha, Physica B: Condensed Matter 407, 1533 (2012). 